\title{
Geleneksel ve Tamamlayıcı Tip (GETAT) Uygulamalarında Enfeksiyon Kontrol Önlemleri, Hijyen ve Çalışan/Hasta Güvenliği
}

\author{
Infection Control Measures, Hygiene and Employee / Patient Safety in Traditional \\ and Complementary Medicine (T\&CM) Applications
}

\author{
Hande Toptan ${ }^{1}$, Tuğba Kaya ${ }^{1}$, Selma Altındiş ${ }^{2}$ \\ ${ }^{1}$ Sakarya Üniversitesi Tip Fakültesi Tibbi Mikrobiyoloji AD. Sakarya \\ ${ }^{2}$ Sakarya Üniversitesi İșletme Fakültesi Sağllk Yönetimi AD. Sakarya
}

\author{
Yazı̧sma Adresi / Correspondence: \\ Arş. Gör. Uzm. Dr. Hande Toptan \\ Sakarya Üniversitesi, Tıp Fakültesi, Tibbi Mikrobiyoloji Anabilim Dalı ve Tıbbi Viroloji Anabilim Dalı, Sakarya \\ E-mail: : handetoptan@sakarya.edu.tr \\ Orcid \\ Hande Toptan : https://orcid.org/0000-0001-6893-8490 \\ Tuğba Kaya : https://orcid.org/0000-0003-2017-481X \\ Selma Altındiş : https://orcid.org/0000-0003-2805-5516
}

Geliş Tarihi / Received : 19-09-2019

Kabul Tarihi / Accepted : 21-09-2019

Yayın Tarihi / Online Published: 30-09-2019

Toptan H., Kaya T., Altındiș S., Geleneksel ve Tamamlayıcı Tıp (GETAT) Uygulamalarında Enfeksiyon Kontrol Önlemleri, Hijyen ve Çalışan/Hasta Güvenliği, J Biotechnol and Strategic Health Res. 2019;3(Özel Sayı):168-172 DOI: bshr.622368

Öz

Amaç Geleneksel ve tamamlayıcı Tip (GETAT) uygulamaları, ilgili alanda sertifikası bulunan hekim ve/veya diş hekimi sorumluluğunda ve Sağlık Bakanlığınca yetkilendirilmiş merkezlerde yapılması gerekmektedir. Eğitimler esnasında standart enfeksiyon kontrol önlemleri/hijyen ve enfeksiyonlarla alakalı temas bilgisi verilmekte birlikte yetersiz olabileceği düșünülmektedir. Bu çalıșmada GETAT uygulayan hekimlere klinikte enfeksiyon kontrol önlemleri/hijyen kurallarının önemini hatırlatma ve vurgulama amacıyla onların bilgi, tutum ve davranışlarının belirlenmesi amaçlanmıștır.

Gereç ve Çalışma, demografik bilgiler ve literatürden destek alınarak hazırlanan GETAT kliniğinde hijyen uygulamalarını sorgulayan dijital anket ile hekimlere ulaşılmış, onların

Yöntemler konu ile alakalı bilgi tutum ve davranışları belirlenmeye çalışılmıștır. Edinilen veriler istatistiksel olarak irdelenmiştir.

Bulgular Toplam 103 katılımcının \%54.4 erkek, \%46.6 Pratisyen hekim, \%9.7 aile hekimi olup \%38.8'inin hekimlik tecrübesi 20 yll ve üzerindedir. Hekimlerin \%95’i en az bir GETAT sertifikasına sahip olup en çok alınan sertifika \%64.3 oranında hacamat(kupa), \%45.9 akupunktur, \%34.7 ozon tedavisi, \%33.7 sülük tedavisi olarak belirlenmiștir. Katılımcıların \%92.8'i hepatit B aşısı, \%49.5'i tetanoz așısı, \%22.7’si de grip așlarını yaptırmıs olup \%54.5'inin AntiHBs titresi 10 IU'nun üzerindedir. Hekimlerin \% 65.7'si Kesici delici aletleri özel atık torbalarında, \%11.8'i ise kırmızı renkli tıbbi atık poșetlerinde biriktirmekte ya da zararsız hale getirmektedir. Katılımcıların \%57.0'si “delici kesici olmayan aletleri” kırmızı renkli tıbbi atık poșetlerine, \%28.0’i tüm atıklarla aynı poșete atmaktadır. Hekimlerin \%72.5’i GETAT uygulamalarında enfeksiyon kontrol önlemleri/hijyen konusundaki bilgi düzeyini yeterli bildirmis, \%86.2'si GETAT’ta yeterli hijyen kuralları uygulanmazsa Hepatit, HIV'in bulasmasına neden olabileceğini düşünmektedir. GETAT uygulamalarından önce hastaların Hepatit B, C ve HIV test durumlarını soranlar \%65.6 iken, \%71,6'sı Hepatit B, C ya da HIV (+) bir hastaya GETAT uygulamasında yaklaşımının değişebileceğini ifade etmiștir. Hastaya temas eden tüm malzemelerin tek kullanımlık olduğunu belirtenlerin oranı \%73.0 iken \%37.6’sının enfeksiyon hastalıklarına karșı sürekli koruyucu ekipman kullandıklarını; \%61.3’ü ise klinikte eldivensiz çalıșmadığını belirtmișlerdir. Hekimlerin \%21.0’i GETAT uygulamalarının enfektif komplikasyonları olabileceğini ifade etmiş, \%50.5’i delici kesici alet yaralanmalarında uygulanacak bir enfeksiyon kontrol prosedürü varlığını bildirirken, \%35.6’sı son 5 yılda klinik içinde delici kesici alet yaralanmasına(iğne batması vs.) 1-3 kere maruz kaldığını bildirmiştir. Katılımcıların yarısından fazlası(\%54.5) "GETAT uygulamaları ve hijyen" konusunda, ek bir eğitime gereksinim duyduklarını belirtmiștir.

Sonuç Hijyen, tıbbi atık ve kan yolu ile bulașan enfeksiyonlardan korunmada ilave eğitimin anlamlı olacağı belirlenmiștir.

Objective Traditional and complementary medicine (T\&CM) applications should be performed under the responsibility of the physician and / or dentist who is certified in the relevant field and in the centers authorized by the Ministry of Health. During the trainings, standard infection control measures / hygiene and contact information related to infections are given and thought to be inadequate. In this study, it was aimed to determine the knowledge, attitudes and behaviors of TひCM physicians in order to remind and emphasize the importance of infection control measures / hygiene rules in the clinic. attitudes and behaviors related to the subject were determined. The data obtained were analyzed statistically.

A total of 103 participants were $54.4 \%$ male, $46.6 \%$ general practitioner, $9.7 \%$ family physician and $38.8 \%$ had a professional experience of 20 years or more. $95.0 \%$ of physicians have at least one T⿱ $\mathrm{CCM}$ certificate and the most obtained certificate was determined as $64.3 \%$ hijama (cupping therapy), $45.9 \%$ acupuncture, 34.7\% ozone treatment and $33.7 \%$ leech treatment. $92.8 \%$ of the participants had hepatitis B vaccine, $49.5 \%$ had tetanus vaccine and $22.7 \%$ had flu vaccines. AntiHBs titers against Hepatitis B of $54.5 \%$ were over $10 \mathrm{IU} .65 .7 \%$ of physicians accumulate or render cutter drill tools in special waste bags and $11.8 \%$ in red medical waste bags. $57.0 \%$ of the participants put "non-penetrating tools" in red medical waste bags and $28.0 \%$ in the same bag with all wastes. While $51.5 \%$ of the physicians strongly recommend TəCM applications to others, $72.5 \%$ found that the level of knowledge on infection control measures / hygiene in Te CM applications was sufficient. $86.2 \%$ of physicians think that if adequate hygiene rules are not applied in TઐCM, It may cause hepatitis and HIV transmission. While $65.6 \%$ of the patients were asked about their Hepatitis B, C and HIV test status before TeCM administration, $71.6 \%$ of them stated that their approach to Te CM application could be changed to a Hepatitis B, Cor HIV $(+)$ patient. While $73 \%$ stated that all materials in contact with the patient were disposable and $37,6 \%$ used continuous protective equipment against infectious diseases; $61,3 \%$ reported that they did not work in the clinic without gloves. $21 \%$ of physicians stated that TઐCM may have infective complications. While $50.5 \%$ of the physicians said that we have an infection control procedure to be used in stab wounds, 35.6\% reported that they had been exposed to Sharp penetrating stab injuries 1-3 times in the last 5 years. More than half of the participants (54.5\%) stated that they needed additional hygiene training on ToCM practices. 


\section{Giriş}

Geleneksel ve tamamlayıc1 Tip (GETAT) uygulamaları standart tıbbi bakımın bir parçası olmayan fakat batı tıbbı$\mathrm{n} ı$ destekleyici ve tamamlayıcı yöntemler olarak tanımlanmıştır. Dünya Sağlık Örgütü, GETAT’’ şu şekilde tanımlamaktadır: "Sağlıklı halin devam ettirilmesi kadar sağlığın korunmasında ve fiziksel ve zihinsel hastalıkların teşhisi, iyileştirilmesi veya tedavisi alanlarında da kullanılan fark$l_{1}$ kültürlere özgü teoriler, inançlar ve deneyimlere dayalı bilgi, beceri ve uygulamaların toplamıdır". Bu uygulamalar Sağlık Bakanlığının Geleneksel ve Tamamlayıcı Tıp Uygulamaları Daire Başkanlığı tarafından fitoterapi, akupunktur, kupa terapi, sülük tedavisi, hipnoz, ozon terapi, mezoterapi, apiterapi, proloterapi, osteopati, refleksoloji, homeopati, kayropraktik, larva uygulaması, müzik terapi uygulamaları olarak belirlenmiştir. ${ }^{2}$ Özellikle akapunktur, kupa tedavisi, sülük tedavisi gibi uygulamalar doğaları gereği invaziv girişimleri kapsadığından Hepatit B (HBV), Hepatit C virüsleri (HCV) ve İnsan immunyetmezlik virüsü (HIV) gibi kan yoluyla bulaşan enfeksiyon etkenlerinin bulaşında risk teşkil edebileceği düşünülmektedir. ${ }^{3}$

$\mathrm{Bu}$ çalışmanın amacı HBV, HCV ve HIV gibi kan yoluyla bulaşan enfeksiyon etkenlerinin bulaşında risk faktörü olarak düşünülen GETAT’ı uygulayan hekimlere klinikte enfeksiyon kontrol önlemleri/hijyen kurallarının önemini hatırlatma ve vurgulama amaciyla onların bilgi, tutum ve davranışlarının belirlenmesidir.

\section{Materyal ve Metot}

Çalışmada, literatürden destek alınarak hazırlanan dijital anket ile hekimlere ulaşılmış, onların konu ile alakalı bilgi tutum ve davranışları belirlenmeye çalışılmıştır. Çalışma etik onayı Sakarya Üniversitesi Tip Fakültesi Girişimsel olmayan etik kurulundan alınmıştır. Anket formunun ilk kısmında 5 soru ile demografik veriler, sonrasında 6 soru ile klinikteki uygulamalara dair bilgiler, nihayetinde 20 soruda ise GETAT uygulamaları sırasındaki standart enfeksiyon kontrol önlemleri ve uygulamaları sorgulanmıştır. Edinilen veriler istatistiksel olarak irdelenmiştir.

\section{Bulgular}

Toplam 103 katılımcının \%54.4 erkek, \%46.6 Pratisyen hekim, \%9.7 aile hekimi olup \%38.8'inin mesleki tecrübesi 20 yll ve üzerindedir. Hekimlerim \%95.0'i en az bir GETAT sertifikasına sahip olup en çok alınan sertifika \%64.3 oranında hacamat(kupa), \%45.9 akupunktur, \%34.7 ozon tedavisi, \%33.7 sülük tedavisi olarak belirlenmiştir (Şekil 1).

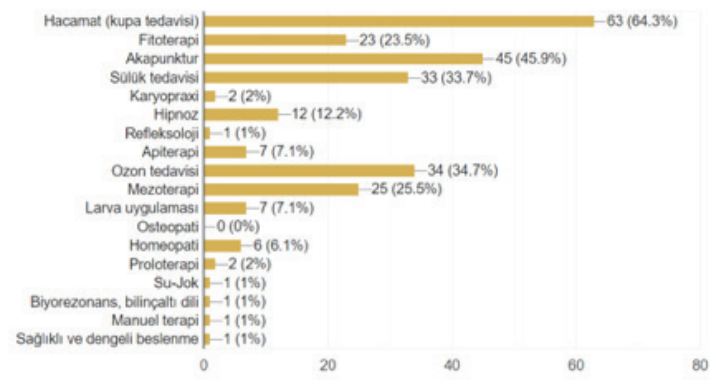

Şekil 1: Katılımcıların GETAT uygulamalarına yönelik aldıkları sertifikaların dağılımı

Katılımcıların \%92.8'i hepatit B aşısı, \%49.5'i tetanoz aşısı, \%22.7’si de grip aşılarını yaptırmıştır (Şekil 2). \%54.5’inin Hepatit B'ye karşı AntiHBs titresi 10 IU'nun üzerindedir. Hekimlerin \%65.7'si kesici delici aletleri özel atık torbalarında, \%11.8'i ise kırmızı renkli tıbbi atık poşetlerinde biriktirmekte ya da zararsız hale getirmektedir. Katılımc1ların \%57.0’si “delici kesici olmayan aletleri” kırmızı renkli tıbbi atık poşetlerine, \%28.0 tüm atıklarla aynı poşete atmaktadır. Katılımcıların sadece \%45.6’sı çalışma arkadaşlarının el hijyeni kurallarına uyduğunu düşünmektedir.

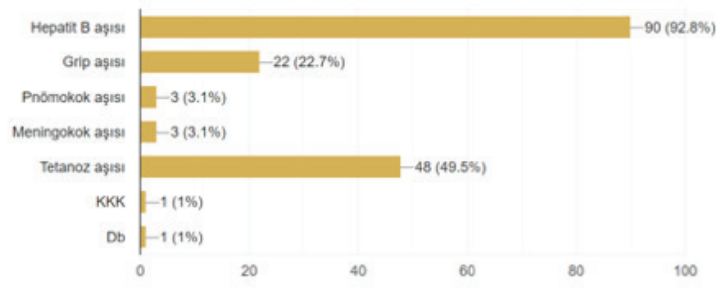

Şekil 2: Katılımcıların yaptırdıkları aşılar

Çalışmaya katılan hekimlerin \%51.5’i GETAT uygulamalarını başkalarına kesinlikle tavsiye etmektedir. "GETAT uygulamalarında enfeksiyon kontrol önlemleri/hijyen 
konusundaki bilgi düzeyini yeterli buluyor musunuz?" sorusuna \%16.7'si kesinlikle evet, \%53.9'u evet olarak yanıt vermiştir (Şekil 3).

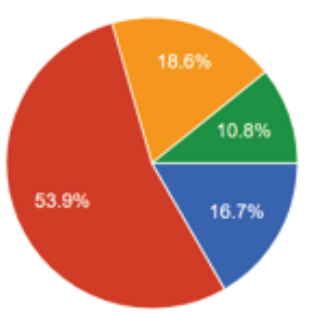

$$
\begin{aligned}
& \text { Kesinlikle Evet } \\
& \text { Evet } \\
& \text { Fikrim Yok } \\
& \text { Hayır } \\
& \text { Kesinlikle Hayır }
\end{aligned}
$$

Şekil 3: Katılımcıların GETAT uygulamaları/Standart enfeksiyon kontrol önlemleri(hijyen) konusundaki bilgilerini yeterli bulma düzeyleri

Hekimlerin \%86.2'si GETAT'ta yeterli hijyen kuralları uygulanmazsa Hepatit, HIV’in bulaşmasına neden olabileceğini düşünmektedir. GETAT uygulamalarından önce hastaların Hepatit B, C ve HIV test durumlarını soranlar \%65.6 iken, \%71,6's1 Hepatit B, C ya da HIV (+) bir hastaya GETAT uygulamasında yaklaşımının değişebileceğini ifade etmiştir.

Hastaya temas eden tüm malzemelerin tek kullanımlık olduğunu belirtenlerin oranı \%73 iken \%37.6'sının enfeksiyon hastalıklarına karşı sürekli koruyucu ekipman (eldiven, maske, tek kullanımlık kıyafet, bone...) kullandıklarını; \%61.3'ü klinikte eldivensiz çalışmadığını belirtmişlerdir (Şekil 4). Katılımcı hekimlerin \%80.2'si eldiven kullanırken de temiz/kirli alan temaslarına dikkat ettiğini ifade etmiştir. Hekimlerin \%21.0’i GETAT uygulamalarının enfektif komplikasyonları olabileceğini ifade etmiştir. \%50.5'i delici kesici alet yaralanmalarında uygulanacak bir enfeksiyon kontrol prosedürümüz var derken \%35.6'sı son 5 yılda klinik içinde delici kesici alet yaralanmasına (iğne batması vs.) 1-3 kere maruz kaldığını bildirmiştir.

Çalışma ortamındaki iş yükünün koruyucu ekipman kullanımına engel olmadığını düşünenlerin oranı \%28.0 iken bazen engel olduğunu düşünenler \%37.0'dir.

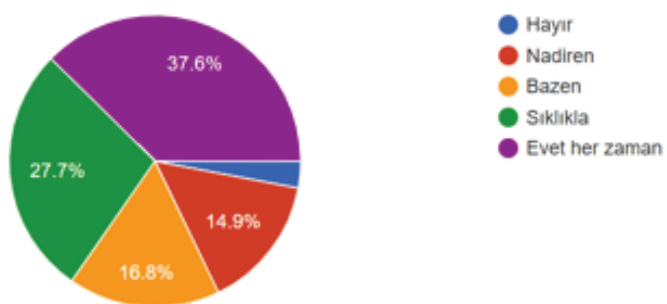

Şekil 4: Katılımcıların GETAT uygulamalarında kişisel koruyucu ekipman (eldiven, maske, kıyafet vs) kullanım oranları.

Hekimlerin \%90.3'ü GETAT uygulamalarında halen bazı resmi düzenlenmeler beklediklerini ifade etmiş, yarısından fazlası(\%54.5) “GETAT uygulamaları ve hijyen” konusunda, ek bir eğitime gereksinim duyduklarını belirtmişlerdir.

\section{Tartışma}

Kupa tedavisi uygulamasının HIV, hepatit B ve hepatit C enfeksiyonları dahil olmak üzere kanla bulaşan enfeksiyonlarda önemli bir risk taşıdığını ifade eden bazı çalışmalar bulunmaktadır. 357 klinik çalışmanın meta-analizi, kupa tedavisinin hepatit $\mathrm{C}$ enfeksiyonunun bulaşmasında kesin bir risk faktörü olduğu sonucuna varmıştır. ${ }^{4}$ Uygulanan kupa tedavisinin, hastaların önemli bir bölümünde bulaşma şekli olduğunu ortaya çıkarmıştır. ${ }^{5}$

Kan yoluyla bulaşan enfeksiyonların bulaşında sülüklerin de etken olabileceği konusunda yayınlar mevcuttur. Sülüğü ayırma sırasında kimyasal maddeler ya da cerrahi forsepsler kullanıldığında sülük, mide içeriğini yaranın içine hapsetme eğilimindedir. Narendranathan ${ }^{6}$, serbest yaşayan sülüklerin $\mathrm{HBV}$ için potansiyel vektörler olması dolayısıyla sülük tedavisi sonrası hepatit B virüsü (HBV) enfeksiyonu geçirme olasılığını bildirmiştir.?

Teorik olarak, kanla bulaşan tüm virüsler potansiyel olarak akupunktur yoluyla bulaşabilir. Literatürde en iyi belgelenmiş vakalar hepatit B virüsü ve daha az olarak da hepatit C virüsü ve HIV'e aittir. ${ }^{8-11}$ Akupunkturla ilişkili kan kaynak- 
lı virüs enfeksiyonları vakalarının çoğu, hastadan hastaya bulaş şeklindedir. Bazen enfeksiyon, virüsü hastaya taşıyan akupunktur uzmanından bulaşabilmektedir. Tüm bu durumların sorumlusu, yeterince sterilize edilmeyen yeniden kullanılabilir akupunktur iğnelerinin kullanımıdır. Tek kullanımlık iğnelerin kullanımının artması sonucunda, akupunkturla bulaşan kan kaynaklı virüslerin görülme sıklı̆ıının azalması beklenmektedir.

Akupunkturla bulaşan enfeksiyonları önlemek için, uygun enfeksiyon kontrol kılavuzlarına sıkı bir şekilde uymak zorunludur. Akupunkturun uygun prosedürlerini yerine getirmek için kurallar olsa da, bu tür kuralların gelişmiş ülkelerde bile uygulanması istenilen seviyede değildir. Akupunktur ile hastalara mikropların bulaşmasını önlemek için, akupunktur yapanlar, hepatit B virüsüne karşı aşılanmalı ve iğnelerin keskinliğini hastalara koymadan önce kendi derileri üzerinde test etmemelidirler. Hastadan kanla bulaşan virüs bulaşmasını önlemek için tek kullanımlık akupunktur iğnelerinin kullanımı kesinlikle takip edilmelidir. Hastadan hastaya kan yoluyla bulaşan virüsler nedeniyle iğnenin yeniden kullanımı önerilmemelidir. ${ }^{12}$

HBV, bulaşıcıllğı en yüksek olan viral hepatit etkenidir. Gözle görünür kan olmadığı durumlarda da bulaşabilir. HBeAg pozitif bir hastanın kanıyla kontamine iğne ile yaralanma durumunda bulaş riski \%22-31 iken HBeAg negatif olduğunda bu oran \%1-6'dır. ${ }^{13} \mathrm{HBV}$ bulaşının önlenmesi için sağlık çalışanlarına HBV aşısı yapılması ve anti HBs titresinin $\geq 10 \mathrm{IU} / \mathrm{mL}$ olması önerilmektedir. HCV bulaş riski HBV’ye göre daha düşüktür. HCV pozitif bir kaynak ile temas sonrası anti-HCV pozitiflik insidansı $\% 1.8^{\prime} \mathrm{dir}^{14}$ Çalışmamızda katılımcı hekimlerin \%71.6'sı hastalarının HBV, HCV veya HIV pozitif olması durumunda yaklaşımlarının değişeceğini belirtmiştir. Benzer şekilde Köseoğlu ve ark. ${ }^{16} 58$ diş hekimi ile yapmış oldukları çalışmada katılımciların \%81.0'inin, HBV, HCV ve HIV ile enfekte olmuş hastaları tedavi ederken bulaş riskinden dolayı endişeli olduklarını ifade etmiştir.
GETAT uygulamalarında hastaya olduğu kadar hastadan hekime bulaşın da önüne geçilmesi oldukça önemlidir. Özellikle akupunktur uygulamalarında tek kullanımlık iğne kullanılmaması ve iğnelerin keskinliğinin hastalardan önce kendi derileri üzerinde test etme gibi durumlarda uygulayıcı hekim de risk altına girmektedir. Güneş ${ }^{15}$ akupunktur uygulaması sırasında hekimin maruz kaldığı mikrobiyolojik riskleri analiz etmek amacıyla yaptığı çalışmada 118 hastanın Hepatit B serolojik verilerini incelemiş ve 25 hastayı Anti Hbs (\%21.0), 5 hastayı ise HBsAg pozitif olarak saptamıştır. Dolayısıyla tek kullanımlık malzeme ve kişisel koruyucu ekipman kullanmanın iki yönlü bulaşı da engelleyeceği çok açıktır. Bizim çalışmamızda da katılımcı hekimler \%73.0 oranında tek kullanımlık malzeme kullandıklarını ifade etmiştir.

Kişisel koruyucu ekipmanların ve özellikle eldivenlerin uygulayıcı hekimi koruması kadar hasta bulaşının önüne geçtiği de bilinmektedir. Bu noktada eldivenlerin kontamine olduktan sonra mutlaka değiştirilmesi gerekmektedir. Aksi takdirde çapraz kontaminasyon kaçınılmazdır. Literatürde de kontamine eldivenle bulaş mevcuttur. ${ }^{16}$ Çalışmamızda katılımcı hekimlerin sadece \%45.6’sının çalışma arkadaşlarının el hijyeni kurallarına uyduğunu düşünmesi dikkat çekmektedir. Bu konuda yapılacak eğitimler ve gözlemsel çalışmalarla bu oranın arttırılması gerektiğini düşünmekteyiz.

Kan yoluyla bulaşan viral enfeksiyonların GETAT yoluyla bulaşabileceği birçok çalışma ile gösterilmiştir. Süreçte sanitasyonun iyi kontrolü gereklidir. GETAT uygulayan tıp merkezlerinde evrensel önlemler için güçlü kılavuz ve protokoller bulunmalıdır. Steril tek kullanımlık iğne ve malzemelerin kullanımı, kişisel koruyucu önlemlere dikkat edilmesi ve standart enfeksiyon kontrol önlemlerine uyulmasıyla enfeksiyon bulaşı kolayca önlenebilecektir. 
Journal of BSHR 2019;3(Özel Sayı):168-172

TOPTAN, KAYA, ALTINDIȘ. GETAT Uygulamalarında Hijyen

\section{Kaynaklar}

1. https://www.who.int/traditional-complementary-integrative-medicine/about/en/ Erișim tarihi: 16 Eylül 2019

2. https://getatportal.saglik.gov.tr/TR,24683/geleneksel-ve-tamamlayici-tip-nedir.html Erișim tarihi: 16 Eylül 2019

3. Ray SC, Thomas DL. Hepatitis C. In: Mandell GL, Bennett JE, Dolin R, eds. Mandell, Douglas, and Bennett's Principles and Practice of Infectious Diseases. 8th ed. Philadelphia, PA: Churchill Livingstone Elsevier, 2015: 1904-27.

4. El-Ghitany EM, Wahab MA, Wahab EWA, Hassouna S, Farghaly AG. A comprehensive hepatitis C virus risk factors meta-analysis (1989-2013); Do they differ in Egypt? Liver Int; 2014. Article in Press.

5. Madani TA. Hepatitis C virus infections reported in Saudi Arabia over 11 years of surveillance. Ann Saudi Med 2007;27:191-4.

6. Narendranathan M. Leeches and hepatitis B. Lancet 1992;339:1362.

7. Nehili M, Ilk C, Mehlhorn H, Ruhnau K, Dick W, Njayou M. Experiments on the possible role of leeches as vectors of animal and human pathogens: A light and electron microscopy study. Parasitol Res 1994;80:277-90.

8. Karmochkine, M., Carrat, F., Dos Santos, O., Cacoub, P., \& Raguin, G., A case-control study of risk factors for hepatitis $C$ infection in patients with unexplained routes of infection. J Viral Hepat, 2006;13(11):775-782, ISSN 1352-0504

9. Karaca, C., Cakaloğlu, Y., Demir, K., Ozdil, S., Kaymakoğlu, S., Badur, S., \& Okten, A. Risk factors for the transmission of hepatitis $C$ virus infection in the Turkish population. Dig Dis Sci, 2006;51(2): 365-369, ISSN 0163-2116

10. Walsh, B., Maguire, H., \& Carrington, D. Outbreak of hepatitis B in an acupuncture clinic. Commun Dis Public Health, 1999;2(2):137-140, ISSN 1462-1843

11. Wiwanitkit, V., HIV infection after Chinese traditional acupuncture treatment. Complement Ther Med, 2003;11(4): 272, ISSN 0965-2299

12. Woo, P.C., Lin, A.W., Lau, S.K. and Yuen, K.Y. Acupuncture transmitted infections. British Medical Journal, 2010;340: 1147-1152.

13. CDC. Guidance for Evaluating health-care personnel for hepatitis B virus protection and for administering postexposure management. MMWR 2013;62:10.

14. U.S. Public Health Service. Updated U.S. Public Health Service Guidelines for the management of occupational exposures to HBV, HCV, and HIV and recommendations for postexposure prophylaxis. MMWR Recomm Rep 2001;50(RR-11):1-52.

15. Güneş A. E., Akupunktur tedavisi strasında doktorun aldığı mikrobiyolojik risklerin analizi: tek merkezli çalıșma. Uluslararası geleneksel ve tamamlayıcı tıp kongresi 19 - 22 Nisan 2018 / İstanbul

16. Piro S, Sammud M, Badi A et al. (2001). Hospital - acquired malaria transmitted by contamined gloves. Journal of Hospital Infection 47(2):156-158. 